\title{
A framework for practical and effective eco-labelling of food products
}

\author{
Tzilivakis, J. ${ }^{1}$, Green, A. ${ }^{1}$, Warner, D. J. ${ }^{1}$, McGeevor, K. $^{2}$ and Lewis, K. A. ${ }^{1}$
}

1. Agriculture and Environment Research Unit (AERU), School of Life Sciences, University of Hertfordshire, UK.

2. Policy Studies Institute, University of Westminster, London, UK.

\begin{abstract}
The pressure on the food industry, and society as a whole, to evolve towards more sustainable production and consumption, particularly with respect to environmental impacts, has increased in recent years. There are a number of drivers that can help reduce environmental impacts including legislative instruments, retail marketing and consumer choices and demand. One driver that has received attention in recent years is the use of product labels, either on a single issue (e.g. carbon) or on multiple issues (e.g. using omni-labelling). This paper reports on a framework that has emerged from a wider study that explored effective approaches to environmental labelling of food products. The wider study found that although the science is not sufficiently robust to develop an outcome-based, environmentally broad, omni-label at this time, there will continue to be a role for environmental labelling in conjunction with other initiatives to improve the sustainability of food production and consumption. The framework presented aims to support this role and help improve the practicality and efficacy of environmental labels. This framework provides a series of interrelated guidelines which aim to provide a basis for development of more effective, robust, credible and practical environmental labels for food products. The framework can be used for designing new, or evaluating existing labelling schemes, to identify opportunities for improvements. The framework is illustrated with an application to four existing schemes.
\end{abstract}

Keywords: agriculture, eco-labelling; environmental label; food; sustainable consumption and production

Acknowledgements: This work has been funded by the Department for Environment Food and Rural Affairs (Defra) in the United Kingdom as part of a wider research project. Defra's support is gratefully acknowledged. The opinions expressed herein are those of the authors, based on the research undertaken, and not necessarily those of the funding body. 


\subsection{Introduction and background}

Sustainable consumption and production (SCP) is a key aspect and priority for sustainable development (Defra, 2005) and the food supply chain forms a key part of SCP (GOS, 2011), which in combination with food security has been of increasing concern (Defra, 2010a). The pressure has therefore increased on the food production industry, and society as a whole, to evolve towards more sustainable consumption and production of food, particularly with respect to environmental impacts. These impacts accumulate throughout a production chain from primary production, processing, packing, distribution, retail to end use (consumption and waste management). The potential environmental effects are numerous and can have a range of direct and indirect impacts, both positive and negative (Petchey et al., 1995; Skinner et al., 1997; Girardin et al., 2000; Withers and Lord, 2002; Defra, 2003; Pretty et al., 2000 and 2005; Roy et al., 2008; Schau \& Fet, 2008; Watkiss, 2009). The effects/impacts include greenhouse gas emissions and climate change, damage to wildlife habitats and biodiversity, pollution of water, soil and air and consequent degradation of the quality of these media, landscape degradation, the production of waste and its consequent disposal and the consumption of non-renewable or scarce resources. There are also social and economic issues to consider such as worker health and welfare, fair trade and animal welfare, and of course we need to produce enough food to feed a growing global population. Therefore there are significant challenges to reducing the environmental footprint of food production within the context of SCP and food security.

There are a number of drivers that may help reduce environmental impacts including legislative instruments, voluntary agreements between producers and retailers, and shifting consumer demand. One driver that has received attention in recent years is the use of product labels, whereby the environmental 'credentials' of a product are communicated to the consumer. This may be on a single issue (e.g. its carbon footprint) or on multiple issues. In relation to the latter, the concept of omni-standards and omni-labelling has emerged (Lang, 2008; Upham et al., 2011). Omni-labels seek to convey information on a range of different environmental impacts (and ethical issues), integrating these into a single, easy to understand format and leaving consumers free to decide for themselves which impacts are the most important to them (MacMillan et al., 2010). However, the science and practice of using labels to drive changes in consumer and industry behaviour is complex and varies according to label type (e.g. some labels are outcome-based and aim to present actual impacts, whereas as others are more practice-based and focus on production standards and practices). There are many issues to tackle including scientific credibility, robustness, and consumer perception of what such labels actually mean and how they are used. There is also a lack of consistency in approaches to labelling which can compound issues. Consequently, there is a need to improve the practicality and efficacy of environmental labels and to understand some of the specific issues that relate to labelling of food.

To address some of these gaps in knowledge and to find ways of improving the practicality and efficacy of environmental labels on food, a study was undertaken for to explore effective approaches to environmental labelling of food products. This paper describes the framework that emerged from this study, which provides a series of interrelated guidelines which aim to provide a basis for developing more effective, robust, credible and practical environmental labels for food products.

\subsection{The framework}

\subsection{Introduction}

Figure 1 provides an overview of the key aspects, interactions and potential role that an environmental label may have. This is a simplified perspective, but it provides a clear basis for understanding how a label may operate in the context of consumers, industry and ultimately the impact on the environment from consumption and production. 


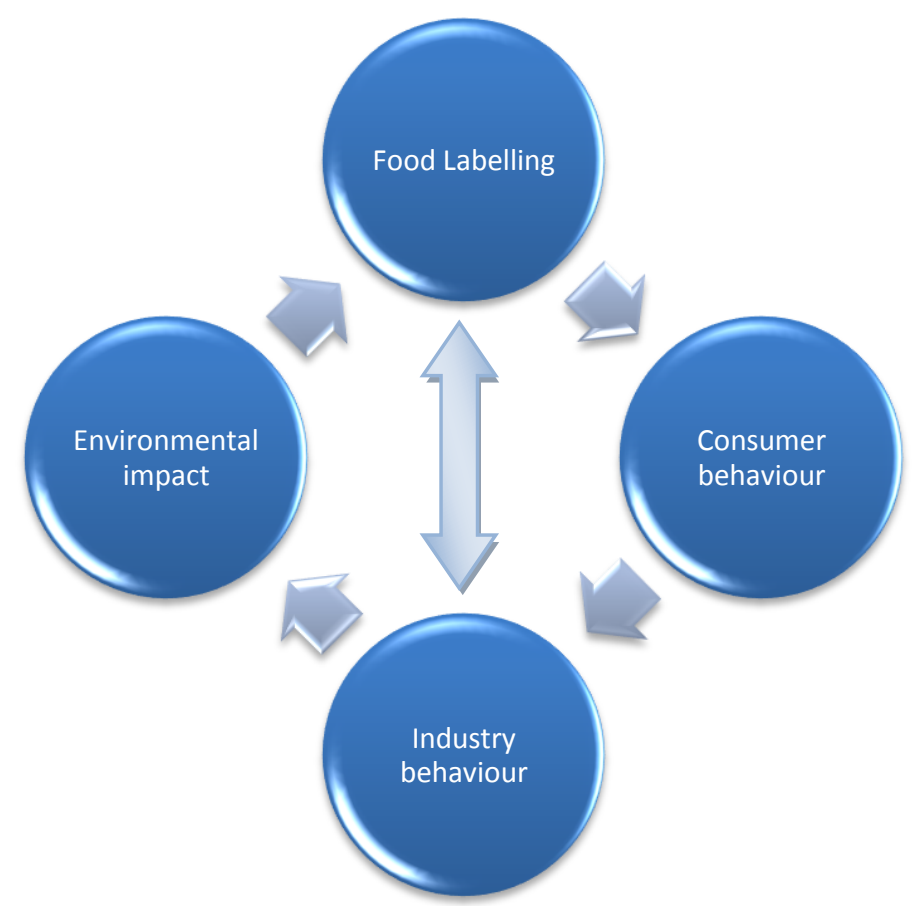

\section{Figure 1: Key aspects to consider for environmental labelling of food and an overview of their interactions}

Figure 1 shows how food labelling can potentially influence both consumer and industry behaviour. In the case of industry, this can be directly (by efforts to meet label requirements) and indirectly via consumer choices. In turn, changes in behaviour in the industry should manifest themselves in changes in practices and ultimately benefits and burdens on the environment. Finally, any environmental label for food needs to credibly and robustly reflect the environmental impact of the product - thus completing the cycle, and a process that hopefully would lead to continuous improvements and progress towards more sustainable food production and consumption.

The principle aim of the framework is to provide a logical and systematic structure for the purpose of either examining existing or designing new environmental labelling initiatives, from the perspective of ensuring labels are credible, robust, practical and effective in relation to their aims and objectives and the key aspects outlined in Figure 1. Consequently, an interdisciplinary and holistic approach is required to tackle the socio-economic and environmental complexities.

The framework draws upon a diversity of environmental, social and economic aspects that have been explored as part of a wider study (Lewis et al., 2010a and 2010b; MacMillan et al., 2010). These included the issues involved with respect to scientific and technical approaches to environmental labelling, the potential of labels as a driver for change both in terms of the behaviour of consumers and stakeholders in the supply chain and the likely costs and benefits to the industry. The findings from this work have been distilled into a set of interrelated guidelines that any labelling scheme for food should aim or aspire to address. Although interrelated, the guidelines can be allocated to four broad areas: (1) Objectives and purpose; (2) Mechanisms and drivers; (3) Practicalities; and (4) Communication. Each of these areas are discussed and explored in the following sections and a number of guidelines have been drawn out in each area to constitute the framework.

\subsection{Objectives and purpose}

Firstly, determining the objectives and purpose is a key aspect for any labelling scheme as they fundamentally govern the scheme and thus influence the other guidelines that should be applied. For example, the purpose may be to market 'greener' products to obtain a market advantage and/or a price premium; to raise consumer awareness of the environmental impacts 
of their food and enable more informed purchase decisions; to address specific environmental issues; or all of these. If the purpose of a scheme is unclear or not very transparent, it can result in a confused understanding of what the label represents and thus can undermine the credibility of the label. Clearly this is a fundamental issue and so provides the first 'objectives and purpose' guideline for the framework:

\section{Guideline 01: The objectives and purpose of the scheme need to be clear and} transparent.

If the purpose of the label is purely for marketing, then the Defra's guidance for making 'green claims' (Defra, 2010b) probably applies rather than guidelines described herein, although there is scope to utilise these guidelines to help support and improve the reputation of a marketingoriented label. However, if the purpose is to reduce or address specific environmental impacts, then some additional guidelines can be applied.

In theory, any environmental label should be based on the most significant environmental impacts associated with the life cycle of a product or the production system from which it was produced. This would be in line with the criteria used in regulations governing the EU eco-label (Regulation (EC) No. 66/2010). However, in reality, the choice of impacts is governed by what can be technically measured and assessed within the confines of a reasonable cost for data collection (see practicality guidelines). It can also be argued that the impact categories should include socio-economic as well as environmental impact categories in order to provide a more holistic perspective and one that relates more to sustainability issues. Sustainability is about striking a balance between environmental, social and economic issues, so labels addressing multiple impacts within all of these areas (such as an omni-label) are likely to be more effective at contributing towards sustainability objectives than single-issue labels. However, this could result in many impact categories, each of which have technical and cost issues associated with them, some of which may prevent those impacts from being included within the labelling scheme. Consequently it is essential to be clear about what environmental (or other) impact areas the label covers, as in many instances it probably will not cover all impacts. This provides the second 'objectives and purpose' guideline:

Guideline 02: The impact categories covered by the scheme or label need to be clearly stated.

The choice of impact categories is also governed by what can be communicated in the context of a label (see communication guidelines), which in itself is connected to what the purpose of the label is (Guideline O1). The practicality guidelines also influence what can be communicated, as it may not be possible to cover all the most relevant categories in a single label (due to lack of data, methodologies, expense, difficulties synthesising simple labels, etc.). Therefore it is very important to set out what is covered and what is omitted from the scheme.

In order to judge how effective a labelling scheme is, performance metrics are required by which to judge any changes in relation to the objectives and purpose of the labelling scheme. The metrics may be outcome or practice-based. For example, are there any specific outcomes the label should contribute to, e.g. reducing emissions, improving water quality, etc. or have practices been changed to required standards. Such metrics need to be clearly identified and form the basis for assessing effectiveness. Additionally, these metrics may be part of the labelling scheme itself, in that they may be used as part of the certification process, e.g. adopting certain production practices to meet scheme rules or requirements. As such they are related to the communication guidelines and so it is important to be able to identify how any targets are driving change in relation the scheme objectives (Guideline O1). The metrics are also related to the mechanism guidelines, in that it is crucial to be able to attribute or allocate any changes in the performance metrics to the effect of the labelling scheme when other initiatives may also be having an effect. This provides the third 'objectives and purpose' guideline: 
Guideline 03: The performance metrics need to be clearly identified.

It can be seen from the above that many of the guidelines are interconnected and govern each other. For example, Guideline $\mathrm{O} 3$ is strongly related to Guideline $\mathrm{O} 2$, and as such it is also governed by what is technically feasible within reasonable costs (practicality guidelines). The purpose and objectives of the scheme also relate to the mechanisms by which the scheme operates.

\subsection{Mechanisms and drivers}

As shown in Figure 1, some schemes aim to change consumer purchasing behaviour via labelling which in turn may exert market pressure on industry resulting in a change in industry practices. Other schemes aim to directly change industry behaviour, and others aim to influence both consumer and industry behaviour. This is an important distinction, as changing industry and consumer behaviour are distinct objectives and the options that work best for one may not necessarily work best for the other (MacMillan et al., 2010). Therefore, it is important to be clear about which approach is to be utilised as this may impact upon the guidelines for communication. The choice of mechanism is in itself part of the purpose and objectives of the scheme, and as such is connected to Guideline 01.

Whether the objective is to change consumer behaviour, industry behaviour or both, it is important to understand the drivers and processes involved between the changes that are instigated and consequent environmental impacts. If the linkages and relationships between the points of intervention and end impacts are unknown, then the scheme may be changing consumer and industry behaviour without a full understanding of the consequences. If we return to Figure 1, there are various points where interventions can be made, which may have an effect on industry and consumer behaviour. In turn, this can have an effect upon industry practices and a subsequent effect and impact on the environment. This 'effect chain' can be simple, but it is often very complex with numerous stressors, midpoints, endpoints and damage categories (Bare and Gloria, 2008; van der Werf, et al., 2009). However, in order to determine how effective a labelling scheme is, it is important to know what impact it has at the point of intervention and what the consequences are in relation to the objectives and metrics identified in Guidelines $\mathrm{O} 2$ and 03 . This provides the first 'mechanisms and drivers' guideline:

Guideline M1: The mechanisms by which the objectives will be achieved need to be clearly identified and understood.

It is important to be able to allocate any impacts to the labelling scheme and/or know what other initiatives are attempting to achieve the same objectives. For example, a labelling scheme may promote the more efficient use of nitrogen fertiliser, and at the same time producers may be subject to Nitrate Vulnerable Zone (NVZ) regulations (SI 2008/2349 \& SI 2009/3160) and inspections imposed by the EU Nitrates Directive (Council Directive $91 / 676 / E E C)$. Similarly a scheme may promote a number of best practices with respect to pesticide use which are also being encouraged, for example in the UK by the Voluntary Initiative (Garratt, and Kennedy, 2006). Therefore the question arises of how to allocate any observed environmental benefits to the labelling scheme, when the NVZ regulations (and inspections) or the activities of the Voluntary Initiative could also be responsible. Hence, it is important to be very clear about what interventions the labelling scheme is implementing, in relation to other initiatives, and what the specific impacts of the interventions are. This provides the second 'mechanisms and drivers' guideline:

Guideline M2: The labelling scheme should complement other initiatives that tackle the same issues and clearly identify any additional benefits specifically provided by the scheme. 
Practice-based approaches to labelling schemes in the food sector are more common than outcome-based systems (Lewis et al., 2010a). This is due to technical difficulties in the metrics (Lewis et al., 2010b) and cost and feasibility issues (MacMillan et al., 2010). However, MacMillan et al. (2010) also identified that outcome-based targets are essential if we are to judge effectiveness, especially with respect to achieving environmental improvements and making progress toward more sustainable consumption and production. Therefore, it is important to understand the role and effect that both process and outcome-based targets have in the context of the labelling scheme with respect to achieving the objectives (Guideline O1). This provides the third 'mechanisms and drivers' guideline:

Guideline M3: The role of practice-based and outcome-based targets and drivers and their relationship with the achievement of scheme objectives needs to be clearly understood.

Practice-based targets do have an important role to play, provided they clearly align with the scheme objectives. The targets can provide useful tools by which to judge the performance of the scheme in relation to its objectives. However, the use of practice-based targets as surrogates for the achievement of outcomes should be avoided unless there is very strong empirical evidence providing a clear link between a practice and an outcome. For example when there is evidence (e.g. Monteny et al., 2006) between some practices and reductions in emissions of greenhouses gases. In many instances these are emissions factors and not direct measurements/observations for a specific product, but they are regarded as an acceptable surrogate for reasons of practicality (see Guideline P2). There is also a danger of miscommunication on the scheme label, whereby practice-based targets are used as surrogates for outcomes achieved, even though the outcomes have not been directly assessed or measured in relation to specific products.

Outcome-based metrics and targets can be independent from any particular scheme, such as indicators used to assess the state of the environment. In theory these could be drawn upon as a means of observing any changes in outcomes in relation to the implementation of practice-based schemes. However, there are still issues of correlating practices implemented with changes in outcomes, both with respect to the empirical evidence linking them and also the allocation of what is causing the change in outcome, i.e. what other practices or initiatives may be contributing (Guideline M2).

Guideline M3 is also connected to the communication guidelines, in that achieving targets may form of the process of obtaining the label/certification, and thus may form part of what is communicated. A key part of this process is the concept of continuous improvement, especially for practice-based targets. A scheme should be dynamic and seek to encourage improvements over time through a process of auditing and action planning. Adopting such a philosophy places a business in a more sustainable position by being more able to respond and adapt.

\subsection{Practicalities}

There are number practicalities that govern what can be done within a labelling scheme and consequently govern many of the guidelines presented herein. These practicalities relate to what is scientifically and commercially feasible in relation the benefits that could be realised.

Firstly, there are a number of limitations in techniques available for measuring environmental impacts that arise over the life cycle of food production (Lewis et al., 2010b). If the objective of the labelling scheme is to contribute towards reducing negative impacts or increasing positive impacts, it is essential that the techniques used to measure and assess these are robust and scientifically sound. If they are not, and inadequate techniques are used, this could be both detrimental to the credibility of the scheme and/or drive the industry in the wrong direction. The use of poor techniques can result in incorrect metrics (Guideline O3) which in turn can result in incorrect targets (Guideline M3). Therefore, it is important to identify the limitations when considering the impact areas that the labelling scheme should cover (Guideline O2) and the metrics that will be used for targets (Guideline O3). When adequate 
techniques are lacking, then this needs to be acknowledged and the objectives of the scheme adapted accordingly. This provides the first 'practicality' guideline:

Guideline P1: Use the best available techniques for measuring and assessing impacts, that are robust and credible.

In order to present information about environmental impacts within the confines of a product label, a lot of data and information needs to be aggregated. In many instances, especially with respect to damage characterisation in LCA (Bare et al., 2000; Jolliet et al., 2004; Pennington et al., 2004; Sleeswijk et al., 2008; UNEP, 2003), the techniques for aggregating environmental impacts are not sufficiently robust to use with limited (if any) validation and in some cases are still at a prototype stage (Lewis et al., 2010b). As such there are technical limits on what can be aggregated. This governs the impact categories that the label can cover (Guideline 02) and what can be communicated. Additionally, the inability to aggregate some environmental impacts to an extent suitable for labelling also contributes towards the lack of feasibility of using outcome-based targets (Guideline M3), and results in the use of practicebased targets and data which is either inherently easier to aggregate or used within a system of pass/fail standards. This therefore provides the second 'practicality' guideline:

Guideline P2: Aggregation of impact data should be limited by the techniques available.

The degree of aggregation may also be governed by the objectives and purpose of the scheme (Guideline 01). If the objective is to raise awareness and educate consumers, then highly aggregated information may not be conducive to this objective, and it may be necessary to provide more detail beyond a simple label or stamp of certification.

An important aspect for any scheme is its cost-benefit performance. The benefits of a labelling scheme may be directly financial, such as a price premium, or they may be indirect or external, such as reduced negative environmental impacts or increases in environmental benefits. Therefore, if a scheme is costly to administer, then the potential benefits need to be greater, with the ideal being high benefits with a low administration cost. There are many cost elements attached to labelling schemes relating to, for example:

- Staffing, facilities and management;

- Administration and membership management;

- Establishing and updating standards;

- Membership fees and data collection costs;

- Costs of auditing, inspection and verification;

- Promotion (advertising, branding, repackaging, graphics, printing, etc.) and consumer support.

Unless the scheme is subsidised in some way, all costs plus a profit margin will be passed to the membership. Therefore producers and industry must be able to clearly identify potential benefits and justify the financial outlay in terms of, for example, increased market share, price premiums, improved customer relations etc.

Research suggests (Bougherara and Combis, 2009; Golan et al., 2001; Melser and Robinson, 2005 ) that the financial costs to industry may not be recoverable as most consumers do not sufficiently care where their food comes from or what the environmental implications of its production are or, where they do, the price premium demanded is not seen as justifiable. Some market-based evidence (Telsei et al., 2002) indicates that consumers can respond to eco-labels if they can relate to the scheme objectives but there is also strong evidence to show that any financial off-setting of the costs against market share or price premium is related to consumer confidence. When confidence is low (e.g. during a recession) then consumers may not be so willing to pay (Clearlyso, 2009; Beef Magazine, 2009; Carrigan and De Pelsmacker, 2009). In addition there are limits to the response that may be expected - not all consumers 
will respond, and those that do will have limits on how much extra they are willing to pay. Therefore the costs that must be met by producers and industry will ultimately govern what the scheme actually does, the impact categories covered and the metrics used (Guidelines O1, $\mathrm{O} 2$ and 03 ), i.e. if the costs of measuring, assessing, verifying and certifying all the significant impacts of a product exceed what can be recovered from a price premium or greater market share, then the scheme objectives need to be tailored or truncated based on to what costs can be absorbed within the current cost of production.

In many instances data within the production chain are based on emission factors or other estimates rather than measured data (Lewis et al., 2010b). This is because it is too costly to measure emissions. For example, it would be possible to measure and monitor methane emissions from each dairy cow but this would be vastly expensive (and impractical), and therefore emission factors are used instead (e.g. Jackson et al., 2009). Whilst this does affect the quality of data that might be used to underpin any label covering greenhouse gas emissions, the use of emission factors provides a more feasible and affordable approach. The use of emission factors, in effect, links practices to outcomes using good empirical evidence, thus addressing the issue raised in Guideline M3 of connecting practices to outcomes. Ideally, all the practicality guidelines should to be considered in conjunction with each other, resulting in the use of techniques that are both the best available (scientifically) and cost-effective.

Outcome-based metrics (Guideline M3) are usually costly to measure and assess but in order for them to be credible they need to be actually measured using robust techniques rather than being based on emission factors. Consequently, there is an inherent conflict between costs and credibility. However, over time, there may be scope to improve the methods and techniques that are available, including those that provide good empirical links between practices and outcomes (discussed above). In so doing, scheme compliance requirements can be refined and made more specific with respect to the activities and practices that need to be monitored and reported.

The above provides the third 'practicality' guideline:

Guideline P3: The financial cost of establishing, administering, managing and participating in the scheme needs to be equitable and commensurate with any potential benefits.

The final practicality guideline is related the third but refers to indirect and hidden costs, and 'nuisance' issues associated with membership of such schemes. It is also strongly governed by the objectives and purpose of the scheme (Guideline 01), as this will define the potential benefits. It may be that the actual financial costs are bearable and the benefits understandable but these must not be outweighed by over complex or bureaucratic processes. A number of these issues have been raised by industry (MacMillan et al., 2010). For example, the amount of paperwork required - this is often a duplication of that required for other schemes and there is often little data sharing occurs because of confidentiality issues. Site visits and inspections also present a burden - where a producer or organisation is a member of several schemes and initiatives many such site visits may be required all of which gather similar data. Collecting the data itself may also be time consuming or complex. There can also be an unfair burden on smaller businesses as they do not have the capacity of deal with the burden of a scheme in comparison to larger businesses.

The scheme should be kept as simple as it needs to be in order to deliver its objectives and the amount of burden placed on producers and industry must be considered. Hence the fourth 'practicality' guideline:

Guideline P4: The burden on industry with respect to scheme application, administration, bureaucracy, verification and inspections needs to be equitable and commensurate with any potential benefits. 


\subsection{Communication}

The final group of guidelines relate to communication aspects of the labelling scheme and thus form the interface between all the data and information gathered within the scheme and the end audience, which may be different depending on the purpose, objectives and the mechanisms by which the scheme operates.

Changing consumer and industry behaviour require different approaches (MacMillan et al., 2010). For example, detailed information on environmental impacts is probably more suited for communication within the industry, such as the use Environmental Product declarations (EPDs) (IEC, 2008), whereas simpler labels may be more suitable for consumer communication. However, it also depends on the purpose of the label, as in some instances more detailed information may be required, for example by consumers with more pro-environmental attitudes (Defra, 2008) who are already well-informed about the environmental impacts of food. As such the approach to communication is governed both by the objectives and purpose of the scheme (Guideline O1) and the mechanisms by which the scheme has chosen to operate (Guideline M1). Consequently, the first 'communication' guideline acknowledges that different approaches may be required depending the objectives, mechanisms and target audience:

Guideline C1: Approaches to communication should be different depending on the target audience.

A label is always going to be a simplified means of communicating something that is, in reality, far more complex. Therefore some degree of aggregation will be involved. However, highly aggregated information on environmental impacts can often be meaningless (Blanc et al., 2008; Booysen, 2002; Salzman, 2003). Labels may range from a simple 'tick' or 'kite mark' (e.g. LEAF Marque, 2008) to indicate that certain standards have been achieved, or it may consist of list of emissions and impacts (e.g. Earthsure, 2009), but in either instance some data and information has been aggregated. Thus it is important to ensure that this aggregation has been done in a credible and transparent way, consistent with the limits of what is technically possible (Guideline P2). Hence, this constitutes the second 'communication' guideline:

Guideline C2: Communication of impacts should be based on data that has been credibly and transparently aggregated.

There are many different ways in which impacts could be communicated on a label. For example, it could be a single label to reflect that the product has met a set of standards (process or outcome-based) or a label that reflects the relative impact in a range of impact categories (like a traffic light system). However, the approach taken should relate back to the purpose and objectives of the label (Guideline 01), in that the purpose of the label may dictate how it is communicated. For example, if the purpose is to raise awareness and educate, then more information may need to be provided on the label, beyond a simple 'kite mark', 'tick' or 'stamp'. In such instances it may be appropriate to provide detailed information. It may be incorrect to assume that consumers need simplified information as people who use labels may already understand them and the others may not use them no matter how they are simplified (MacMillan et al., 2010). This guideline does not dictate any particular design principles for a label, simply that the label should be 'fit for purpose', i.e. designed to meet the objectives of the scheme in the simplest way possible. This provides the third 'communication' guideline:

Guideline C3: Methods of communicating impacts on a label should be as simple as possible.

The final communication guideline relates to the boundaries of the scheme. Consequently there strong connections with the 'objectives and purpose' and 'mechanisms and drivers' guidelines, for example the impact areas it covers (Guideline 02 ). There are examples of carbon labels 
(that promote a single environmental impact i.e. reduction of greenhouse gases or carbon neutrality) that use this as a basis to claim their product has no environmental impact (implying multiple issues are being addressed). If the label only covers one impact area, this should be clear and not ambiguous. Additionally, the system to which the impacts are related requires clear definition i.e. is it a particular brand (e.g. LEAF Marque), a full process life-cycle (production to consumption) or just a sub-process such as manufacturing or on-farm production. This may be governed by the purpose and objectives of the scheme (Guideline O1). Also, the functional unit of any impacts needs to be clear (Lagerstedt et al, 2003; Martínez-Blanco et al., 2010; Smith Cooper, 2003), e.g. per unit weight purchased, per portion as sold, per area of production or per harvested weight. This may be governed by the purpose and objectives of the scheme (Guideline O1). Finally, in relation to Guideline M2, it is important that the labelling scheme complements other initiatives that are tackling the same issues, and to not lay claim to being the sole cause of any benefits. Consequently this provides the final 'communication' guideline:

Guideline C4: The boundaries of what the label covers needs to be clearly communicated.

\subsection{The complete guidelines and framework or practical and effective environmental labelling of food}

Table 1 lists all fourteen of the guidelines that have emerged above from the four groups.

Table 1: Overview of guidelines for practical and effective environmental labelling of food

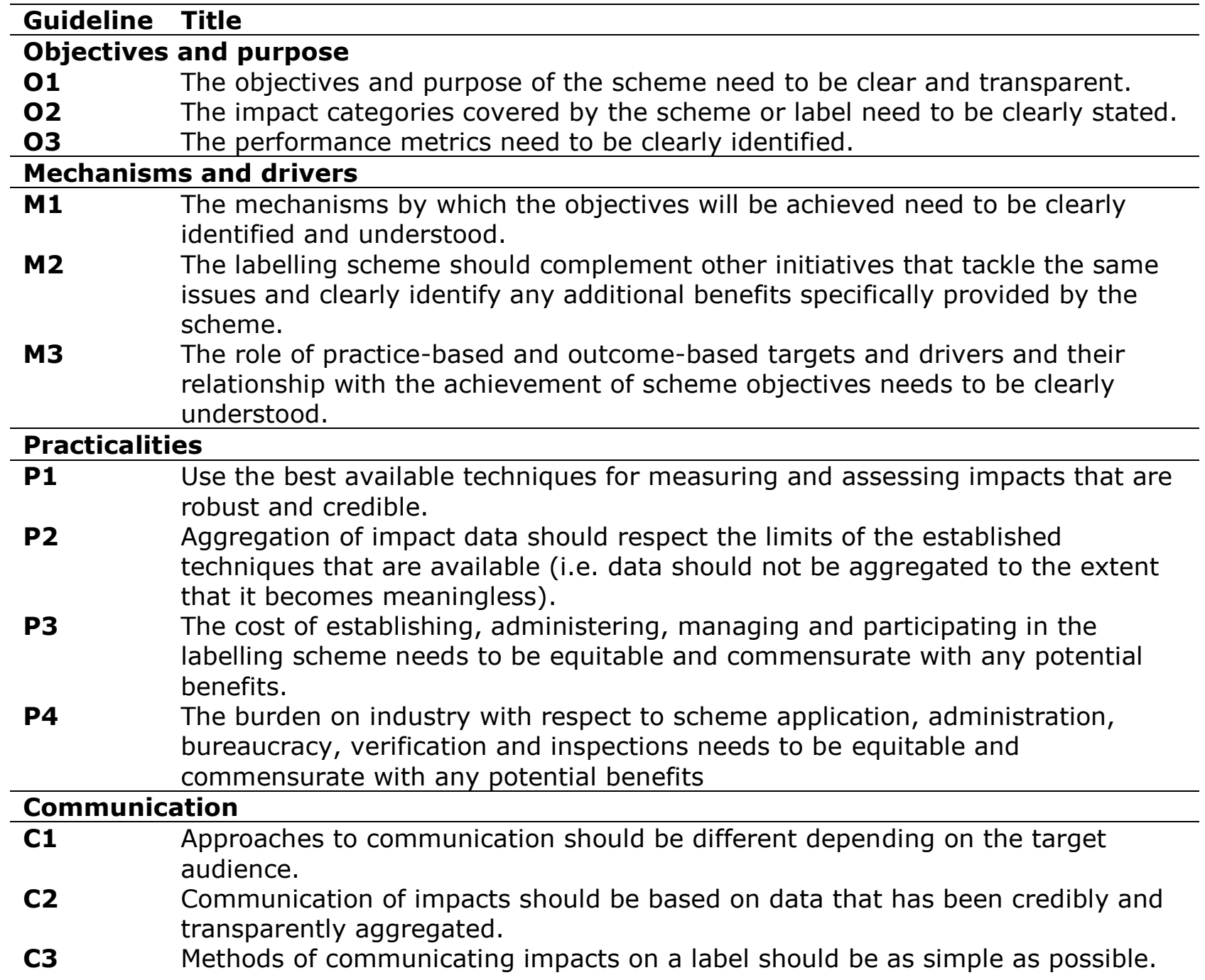




\begin{tabular}{ll}
\hline Guideline & Title \\
\hline C4 & The boundaries of what the label covers needs to be clearly communicated. \\
\hline
\end{tabular}

As has been discussed above, an important aspect to acknowledge is that many of these guidelines are interlinked, and these links determine the practicality and effectiveness of any potential or existing label. Figure 2 shows the interrelationships between the guidelines and it can be seen that the relationships are complex. However, explicitly highlighting these interrelationships provides a better understanding of what constitutes a practical and effective label as this is dependent on some of the choices that are made within each of the guidelines.

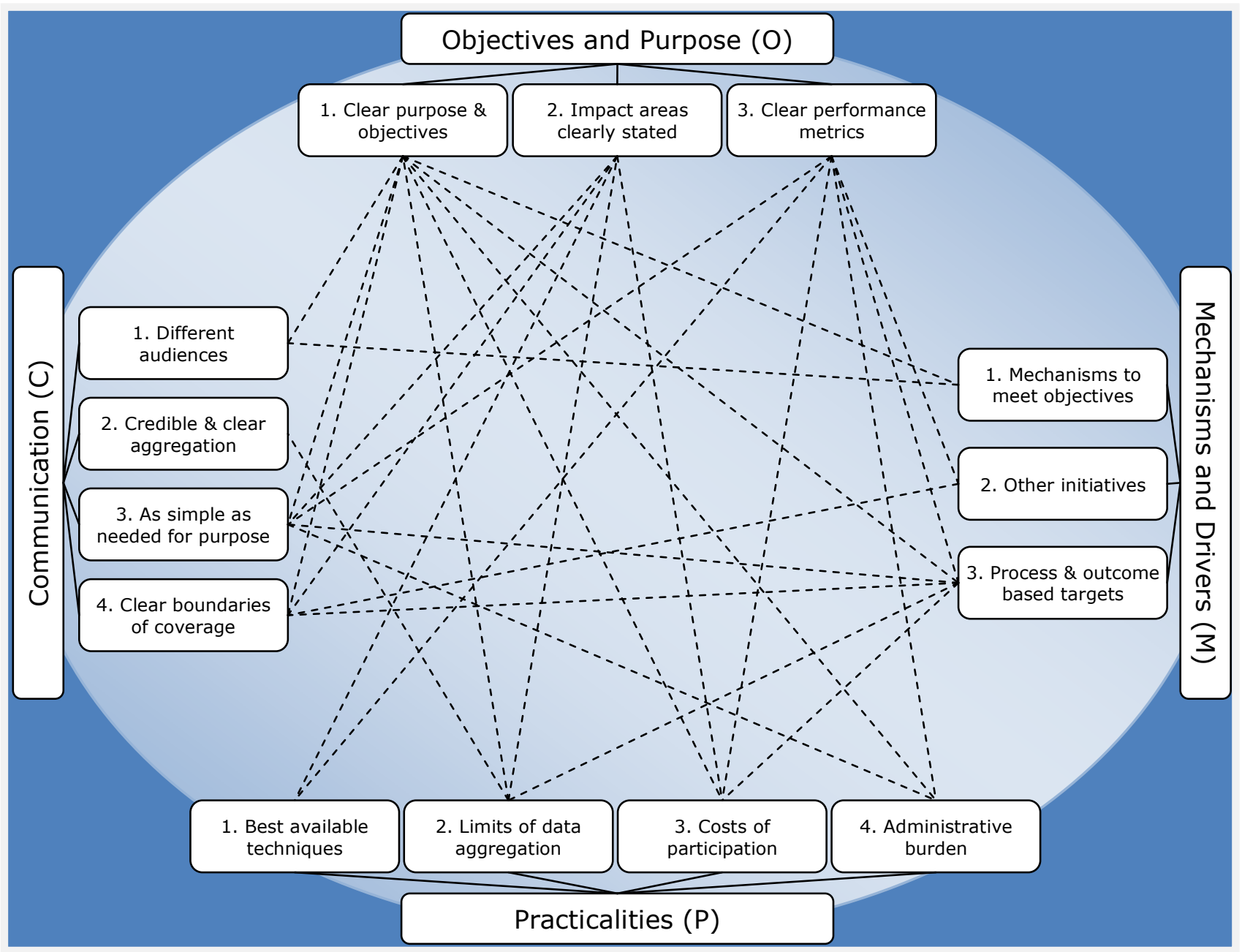

Figure 2: Interrelationships between the guidelines (the "cats-cradle")

The 'cats-cradle' diagram (Figure 2) provides a holistic means for exploring and assessing the practicality and efficacy of an environmental labelling scheme. It explicitly highlights the different aspects and guidelines that need to be considered in conjunction. For example the purpose and objectives of a schemes (O1) relate to the mechanisms (M1) by which the scheme will aim to achieve those objectives, which also relates to the end audience (C1); or the performance metrics (O3) will be governed by the techniques available (P1), which in turn will also govern the impact areas covered by the label (O2) and thus the communication of what the label covers (C4).

\subsection{Application of the framework}

To illustrate how the framework can be applied it has been used to assess four different existing schemes. The schemes are Stichting Milieukeur in the Netherlands (Liefferink, 1996; Andersen and Liefferink, 1997; Zito, 2000; CPI, 2008), Earthsure in the USA (Earthsure, 2009), Indice Carbone in France (CASINO, 2008) and LEAF Marque in the UK (LEAF Marque, 2008). It is not possible to describe fully within this paper how each of the schemes meets the 
guidelines, therefore their compliance with each guideline has been scored 0 to 5 (where 0 corresponds to failing to meet the guideline and 5 is full compliance). The results are shown in Table 2.

\section{Table 2. Performance of different labelling schemes in relation to the guidelines}

\begin{tabular}{lcccc}
\hline Guideline & $\begin{array}{c}\text { Stichting } \\
\text { Milieukeur }\end{array}$ & Earthsure & $\begin{array}{c}\text { Indice } \\
\text { Carbone }\end{array}$ & $\begin{array}{c}\text { LEAF } \\
\text { Marque }\end{array}$ \\
\hline O1. Clear objectives and purpose & 5 & 5 & 5 & 5 \\
O2. Impact areas clearly stated & 2 & 5 & 5 & 1 \\
O3. Clear performance metrics & 2 & 5 & 4 & 2 \\
\hline M1. Mechanisms to meet objectives & 5 & 4 & 5 & 4 \\
M2. Other initiatives & 0 & 0 & 4 & 4 \\
M3. Process and outcome based targets & 1 & 5 & 5 & 3 \\
\hline P1. Best available techniques & 0 & 4 & 5 & 0 \\
P2. Limits of data aggregation & N.A. & 4 & 5 & N.A. \\
P3. Costs of participation & 4 & 1 & 5 & 4 \\
P4. Administrative burden & 5 & 0 & N.A. & 4 \\
\hline C1. Different audiences & 5 & 4 & 5 & 5 \\
C2. Credible and clear aggregation & N.A. & 4 & 5 & N.A. \\
C3. As simple as needed for purpose & 1 & 3 & 2 & 3 \\
C4. Clear boundaries of coverage & 1 & 5 & 5 & 1 \\
\hline Total & 31 & 49 & 60 & 36 \\
\hline Average (for applicable guidelines) & 2.6 & 3.3 & 4.6 & 3 \\
\hline
\end{tabular}

Table 2 shows that all the schemes have clear objectives and purpose. Earthsure and Indice Carbone both have clear impact areas that they cover, with Earthsure having a range of impact categories and Indice Carbone focusing on just greenhouse gas emissions. Stichting Milieukeur and LEAF Marque do not clearly state impact areas as they are both practice based, although the practice-based standards of Stichting Milieukeur are a little more formalised with respect to relating back to impact categories for product categories. The practice-based approach of Stichting Milieukeur and LEAF Marque is also reflected in the low score for performance metrics, whereas Earthsure and Indice Carbone both utilise standardised approaches in their performance metrics which focus on environmental effects and outcomes.

All the schemes have clear mechanisms on how they aim to meet their objectives. Stichting Milieukeur and Indice Carbone focus on influencing consumer behaviour. Earthsure and LEAF Marque focus more on changing industry behaviour, but also aim to influence consumer behaviour to a lesser extent, and as such this results in a slightly confused mechanism. Stichting Milieukeur and Earthsure do not actively compliment other initiatives tackling the same issues. Indice Carbone is consistent with the French Grenelle de l'environnement regulatory approach (Grenelle de l'environnement, 2010) so forms part of a broader approach to solving environmental problems. LEAF Marque integrates with other farm assurance schemes, such as Assured Food Standards (AFS), and also takes into account other initiatives such as cross compliance (RPA, 2010) and entry level stewardship (Natural England, 2010) in order to compliment these. Both Stichting Milieukeur and LEAF Marque aim to bring about improvements in the environmental impact of their products by changing farming practices and hence their targets are practice-based and potential environmental impact is not assessed. In case of Stichting Milieukeur, their principle mechanism is to change consumer behaviour, so not using outcome-based targets results in poor performance for Guideline M3. However, the principle mechanism for LEAF Marque is to change industry behaviour, so practice-based targets are more appropriate and hence its performance for M3 is better, but the lack of assessment of impacts in relation to its aims is still a weak point. Earthsure and Indice Carbone both utilise outcome-based measures and drivers which are used to communicate impacts to both industry and consumers.

Stichting Milieukeur and LEAF Marque do not utilise any impact assessment techniques, so they score zero relation to use the best available techniques. Earthsure and Indice Carbone both use standard and relatively well established techniques for calculating impacts. Earthsure 
covers a broad range of impact areas, and thus in some instances uses techniques that are less well tested and established for some impact categories (Pennington, et al., 2004), whereas Indice Carbone's focus on a single issue of greenhouse gases utilises one of the most established techniques of all impact categories. This picture is also reflected in the techniques used for aggregation. Stichting Milieukeur, Indice Carbone and LEAF Marque all perform well with respect to costs of participation and administrative burden. Stichting Milieukeur has been established for many years and appears to be financially sustainable. The costs of participating in LEAF Marque are relatively low and the any administrative burden is often coupled with management benefits (e.g. completing the LEAF audit can be beneficial from a management perspective). Indice Carbone is fully financed by the CASINO group so there are no direct costs or burdens of agricultural producers. Earthsure is a costly scheme to participate in and as it is relatively new its long term financing remains uncertain, and it is also unclear if the costs of participation can be recouped from improved sales for example.

All the schemes do well with respect on communicating with their respective and different target audiences. The techniques used by Earthsure and Indice Carbone for aggregating data are using the best available techniques and are relatively transparent, especially in the case of greenhouse gas emissions. There are some issues for all the schemes in relation to whether what is communicated is as simple and fit for purpose as it could be. In the case of Stichting Milieukeur, impacts are not communicated and the label just indicates that the product standard has been met. The consumer must source the appropriate product category standard to identify what impact categories have been addressed and for food products that use a practice-based approach this will not be determinable. For Earthsure, detailed data about each impact is presented, which is useful for communication within industry, but this may be too complex for consumers. Indice Carbone's carbon index value is shown on a sliding scale showing what constitutes good and bad allowing consumers to make judgements. However, this is only valuable where fair and scientifically robust product comparisons can be made. LEAF Marque is a recognisable label, but it does not convey what impacts have been addressed by the scheme. In relation to this, both LEAF Marque and Stichting Milieukeur clearly lack defined boundaries of coverage with respect to what issues they are addressing. In the case of Earthsure and Indice Carbone, the coverage is very clear and explicit, with clear impact categories defined in Earthsure and the single focus on greenhouse gas emissions in Indice Carbone.

The total and average scores for the schemes overall are presented at the bottom of Table 2 . This shows that, on an un-weighted basis, the outcome-based schemes of Earthsure and Indice Carbone appear to perform better overall in relation to the guidelines than the practicebased schemes of Stichting Milieukeur and LEAF Marque. It could be argued that some of the guidelines are more important than others and this importance could vary between schemes depending on their objectives. If some guidelines were given more weight on this basis, then a different picture may emerge. However, in this instance the scores have not been weighted in order to maintain a more objective approach. It is also apparent that the higher scoring schemes are not without their weaknesses. In the case of Indice Carbone it is restricted to just the single issue of greenhouse gas emissions. In the context of developing more sustainable production, all impacts should ideally be considered so that one impact is not pursued and improved at the expense of another. Earthsure does cover a broader range of impacts, but there are questions over its financial sustainability and administrative burden - it may be potentially too costly to implement in relation to the benefits that it delivers. Additionally there are some questions that could be raised with some of the less well established techniques used for some impact categories (Lewis et al., 2010b). Stichting Milieukeur and LEAF Marque are both more practical to implement and less costly. However, there are issues associated with what impacts they cover and how this is communicated. The lack of outcome-based metrics and targets may also mean that little progress is made towards actually improving any environmental impacts or any progress is not demonstrable.

The framework has clearly identified the differences between the outcome and practice based schemes and has to some extent looked more favourably on those that have a more outcomebased approach. This is because the framework is endeavouring to highlight schemes that are practical, effective, robust and credible. A more detailed assessment, and one which perhaps 
applies weightings to the different guidelines, might reveal a slightly different picture, but fundamentally the framework has shown an ability to highlight the relative strengths and weaknesses of different schemes and approaches. Practice-based schemes do well in relation to practicality, but they do not score so well with respect to effectiveness (as this is largely unknown) and consequently this raises doubt over credibility and robustness. Therefore it seems that practice-based schemes need to be improved to the extent that they can demonstrate they are effectively delivering outcomes, and outcome-based schemes need to be made more practical and less costly, so that any outcomes delivered are commensurate with the cost of delivery.

\subsection{Discussion and conclusions}

One of the key conclusions of the wider study from which the framework has emerged (Lewis, et al., 2010b) is that currently the science is not sufficiently robust to develop an outcomebased, environmentally broad, omni-label. This is critical to acknowledge, as it highlights that any 'environmental' label probably does not cover all environmental issues. Additionally, in relation to this, it should be noted that the costs of outcome-based, environmentally broad, omni-label may incur could be unacceptably high in relation to the potential benefits that could be realised, particularly since there is lack of evidence on how effective labels are as a tool to stimulate change. However, despite the deficiency in the science, it is anticipated that there will continue to be a role for environmental labelling alongside other initiatives to improve the sustainability of food consumption and production. This is also reflected in the fact that the amount of work that is ongoing regarding environmental labelling, including food labelling, is increasing worldwide despite the limitations (Lewis et al., 2010a).

Labelling does have potential to influence the behaviour of some consumers and can help to encourage producers and manufacturers to reduce their environmental impact. However, the mechanisms by which environmental labelling works are complex and subject to multi-faceted challenges, as illustrated by the 'cats-cradle' of interrelationships in Figure 2. Some of these limitations can be addressed by businesses and third sector organisations involved in labelling, some would require government to take action, while others, such as aggregation problems, are intrinsic to labelling and are likely to persist. However, it is clear that while well-developed environmental labelling can be expected to support consumer awareness of environmental issues and advance best practice in industry, it should not be expected to achieve substantial improvements in performance across the sector on its own. Labelling should be part of suite initiatives that have common goals and complimentary approaches. This will undoubtedly involve public, private and third sector stakeholders working together, with government providing regulatory baselines and facilitating harmonised techniques and the private and third sector providing innovation and sector specific approaches to meet the requirements of the food industry. Just as holistic thinking is required for sustainable development, an integrated and harmonised approach to labelling is required which, in tandem with other initiatives, will help make progress towards more sustainable consumption and production.

The framework and guidelines presented herein have taken all of the issues above into account and attempted to present them in a logical, holistic and systematic way. In so doing it provides a common reference for all stakeholders to explore and assess labelling schemes and make any limitations (such as those outlined above) transparent. It therefore has potential to facilitate the evolution of labelling schemes that are more robust, credible, practical and effective, and do so as part of broader efforts across industry, government and the third sector to address the challenges of sustainable consumption and production and food security that lie ahead.

\section{References}

Andersen, M. S. and Liefferink, D. (eds) (1997) European Environmental Policy. The Pioneers. Manchester: Manchester University Press. 
Bare, J.C. and Gloria, T.P. (2008) Environmental impact assessment taxonomy providing comprehensive coverage of midpoints, endpoints, damages, and areas of protection. Journal of Cleaner Production, 16, 1021-1035.

Bare, J.C., Hofstetter, P., Pennington, D. and Udo de Haes, H.A. (2000) Midpoints versus Endpoints: the sacrifices and benefits. The International Journal of Life Cycle Assessment, 5:6, 319-326

Beef Magazine (2009) Economy brings decline on organic food sales. Available at: http://beefmagazine.com/natural-beef/0211-organic-foods/

Blanc, I., Friot, D., Margni, M. and Jolliet, O. (2008) Towards a new index for environmental Sustainability based on a DALY weighting approach. Sustainable Development, 16, 251-260

Booysen, F. (2002) An overview and evaluation of composite indices of development. Social Indicators Research, 59, 115-151

Bougherara, D. and Combris, P. (2009) Eco-labelled food products: what are consumers paying for? European Review of Agricultural Economics, 36(3), 321-341

Carrigan, M. and De Pelsmacker, P. (2009) Will ethical consumers sustain their values in the global credit crunch? International Marketing Review, 26(6), 674-687

CASINO (2008) The CASINO Carbon Footprint, the 1st complete environmental labelling scheme in France. Available at: http://www.oeitfl.org/UserFiles/File/conference\%202009/voinnesson.pdf

Clearlyso (2009) Sales of organic food slump by up to 30 percent. Available at: http://www.clearlyso.com/newsitem.jsf?id=194

Council Directive 91/676/EEC of 12 December 1991 concerning the protection of waters against pollution caused by nitrates from agricultural sources. OJ L 375, 31.12.1991, p. 1-8

CPI - Confederation of Paper Industries (2008) Environmental Labelling Factsheet

Defra (2003) Strategic review of diffuse water pollution from agriculture. Discussion document. Department for Environment, Food and Rural Affairs, April 2003

Defra (2005) Securing the Future - UK Government sustainable development strategy. Defra Publications, London

Defra (2008) A framework for pro-environmental behaviours. Department for Environment, Food and Rural Affairs, January 2008

Defra (2010a) Food 2030. Department for Environment, Food and Rural Affairs, January 2010

Defra (2010b) Green Claims - Practical Guidance. How To Make A Good Environmental Claim. Department for Environment, Food and Rural Affairs, PB9501c

GOS (2011) Foresight. The Future of Food and Farming. Final Project Report. The Government Office for Science (GOS), London.

RPA (2010) The Guide to Cross Compliance in England. Rural Payments Agency (RPA), rpa157 version 2.0, December 2010.

Earthsure (2009) Earthsure ${ }^{\mathrm{TM}}$ Environmental Product Declarations Program. Revision 1. Available at: http://earthsure.org/Earthsure Program EPDs.pdf

Garratt, J. and Kennedy, A. (2006) Use of models to assess the reduction in contamination of water bodies by agricultural pesticides through the implementation of policy instruments: a case study of the Voluntary Initiative in the UK. Pest Management Science, 62(12), 11381149

Girardin, P., Bockstaller, C. and van der Werf, H. M. G. (2000) Assessment of potential impacts of agricultural practices on the environment: the AGRO*ECO method. Environmental Impact Assessment Review, 20, 227-239

Golan, E., Kuchler, F. and Mitchell, L. with contributions by Greene, C. and Jessup, A. (2001) Economics of Food Labelling, Economics of food labelling. Journal of Consumer Policy, 24, 117-184

Grenelle de l'environnement (2010) Grenelle de l'environnement website, Available at: http://www.legrenelle-environnement.fr/spip.php?rubrique112

IEC (2008) Introduction, intended uses and key programme elements for Environmental Product Declarations, EPD. International EPD Consortium (IEC). February 2008.

Jackson, J., Choudrie, S., Thistlethwaite, G., Passant, N., Murrells, T., Watterson, J., Mobbs, D., Cardenas, L., Thomson, A. and Leech, A. (2009) UK Greenhouse Gas Inventory, 1990 to 2007: Annual Report for submission under the Framework Convention on Climate Change. ISBN 0-9554823-8-0. http://www.airquality.co.uk/reports/cat07/0905131425_ukghgi-90 07_main_chapters_Issue2_UNFCCC_CA_v5_Final.pdf 
Jolliet, O., Müller-Wenk, R., Bare, J., Brent, A., Goedkoop, M., Heijungs, R., Itsubo, N., Peña, C., Pennington, D., Potting, J., Rebitzer, G., Stewart, M., Udo de Haes, H. and Weidema, B. (2004) The LCIA Midpoint-damage Framework of the UNEP/SETAC Life Cycle Initiative. The International Journal of Life Cycle Assessment, 9:6, 394-404

Lagerstedt, J., Luttropp, C. and Lindfors, L. G. (2003) Functional priorities in LCA and design for environment. The International Journal of Life Cycle Assessment, 8:3, 160-166

Lang, T. (2008) Where will all the food come from? Debate at the British Association Festival of Science, Liverpool, 5-10 September 2008.

LEAF Marque (2008) LEAF Marque Global Standard. Version 8.0, issued 01/10/08. Effective from 1st January 2009. Linking Environment And Farming

Lewis, K. A., Green, A., Tzilivakis, J., Warner, D. J., MacMillan, T. and McGeevor, K. (2010a) Literature review. Appendix A in Final report to Department for Environment, Food and Rural Affairs (Defra) for project FO0419 Effective approaches to environmental labelling of food products.

Lewis, K. A., Green, A., Tzilivakis, J. and Warner, D. J. (2010b) Analysis of environmental impacts and their integration and communication. Appendix B in Final report to Department for Environment, Food and Rural Affairs (Defra) for project FO0419 Effective approaches to environmental labelling of food products.

MacMillan, T., McGeevor, K., Durrant, R., Lewis, K. A. and Tzilivakis, J. (2010) Consumer and industry costs, benefits \& behaviour. Appendix C in Final report to Department for Environment, Food and Rural Affairs (Defra) for project FO0419 Effective approaches to environmental labelling of food products.

Monteny, G., Bannink, A. and Chadwick, D. (2006) Greenhouse gas abatement strategies for animal husbandry. Agriculture, Ecosystems and Environment, 112, 163-170

Liefferink, D. (1996) Environmental Policy and the Nation State: The Netherlands, the EU and Acid Rain. Manchester: Manchester University Press

Martínez-Blanco, J., Antón, A., Rieradevall, J., Castellari, M. and Muñoz, P. (2010) Comparing nutritional value and yield as functional units in the environmental assessment of horticultural production with organic or mineral fertilization. The case of Mediterranean cauliflower production. The International Journal of Life Cycle Assessment, In press. DOI: 10.1007/s11367-010-0238-6

Melser, D. and Robinson, P. E. (2005) Eco-labelling and the Trade-Environment Debate. The World Economy, 28(1), 49-62

Natural England (2010) Entry Level Stewardship. Environmental Stewardship Handbook. Third Edition. Natural England, ISBN 978-1-84754-185-7, NE226, February 2010

Pennington, D. W., Potting, J., Finnveden, G., Lindeijer, E., Jolliet, O., Rydberg, T. and Rebitzer, G. (2004) Life cycle assessment Part 2: Current impact assessment practice. Environment International, 30, 721- 739

Petchey, P., D'Arcy, B. and Frost, A. (Eds.) (1995) Diffuse Pollution and Agriculture. Proceedings of a conference held in Edinburgh, 12-14 April 1995. Scottish Agricultural College (SAC)

Pretty, J. N., Brett, C., Gee, D., Hine, R. E., Mason, C. F., Morison, J. I. L., Raven, H., Rayment, M. D. and van der Bijl, G. (2000) An assessment of the total external costs of UK agriculture. Agricultural Systems, 65(2),113-136

Pretty, J. N., Ball, A. S., Lang, T and Morison, J. I. L. (2005) Farm costs and food miles: An assessment of the full cost of the UK weekly food basket. Food Policy, 30, 1-19

Regulation (EC) No. 66/2010 of the European Parliament and of the Council of 25 November 2009 on the EU Ecolabel (OJ L 27, 30.01.2010, pp.1-19)

Roy, P., Nei, D., Orikasa, T., Xu, Q., Okadome, H., Nakamura, N. and Shiina, T. (2008) A review of life cycle assessment (LCA) on some food products. Journal of Food Engineering, 90(1), Pages $1-10$

Salzman, J. (2003) Methodological choices encountered in the construction of composite indices of economics and social well-being. Centre for the Study of Living Standards Report 2004-05, CSLS.

Schau, E. M. and Fet, A. M. (2008) LCA studies of food products as background for environmental product declarations. The International Journal of Life Cycle Assessment, 13(3), 255-264

SI 2008/2349 The Nitrate Pollution Prevention Regulations 2008

SI 2009/3160 The Nitrate Pollution Prevention (Amendment) Regulations 2009 
Skinner, J. A., Lewis, K. A., Bardon, K. S., Tucker, P., Catt, J. A. and Chambers, B. J. (1997) Overview of the Environmental Impact of Agriculture in the UK. Journal of Environmental Management, 50, 111-128

Sleeswijk, A. W., van Oers, L. F.C.M., Guinée, J. B., Struijs, J. and Huijbregts, M. A. J. (2008) Normalisation in product life cycle assessment: An LCA of the global and European economic systems in the year 2000. Science of The Total Environment, 390:1, 227-240

Smith Cooper, J. (2003) Specifying functional units and reference flows for comparable alternatives. The International Journal of Life Cycle Assessment, 8:6, 337-349

Teisl, M. F., Roe, B. and Hicks, R. L. (2002) Can Eco-Labels Tune a Market? Evidence from Dolphin-Safe Labeling. Journal of Environmental Economics and Management, 43(3), 339359

UNEP (2003) Evaluation of Environmental Impacts in Life Cycle Assessment. United Nations Environment Programme. ISBN: 92-807-2144-5.

Upham, P., Dendler, L. and Bleda, M. (2011) Carbon labelling of grocery products: public perceptions and potential emissions reductions. Journal of Cleaner Production, 19, 348-355

van der Werf, H. M. G., Kanyarushoki, C., Corson, M. S. (2009) An operational method for the evaluation of resource use and environmental impacts of dairy farms by life cycle assessment. Journal of Environmental Management, 90(11), 3643-3652

Watkiss, P. (2009) Comparative life-cycle assessment of food commodities procured for UK consumption through a diversity of supply chains. Report prepared for Department for Environment, Food and Rural Affairs (Defra), Project FO0103, by Watkiss Associates, July 2009.

Withers, P. J. A. and Lord, E. I. (2002) Agricultural nutrient inputs to rivers and groundwaters in the UK: policy, environmental management and research needs. The Science of the Total Environment, 282-283, 9-24

Zito, A. and Egan, M. (1998) Environmental Management Standards, Corporate Strategies and Policy Networks. Environmental Politics, 7(3), 94-117 